\title{
Relaxations of fluorouracil tautomers by decorations of fullerene-like SiCs: DFT studies
}

\author{
Alireza Kouchaki ${ }^{\mathrm{a}}$, Oğuz Gülseren ${ }^{\mathrm{b}}$, Nasser Hadipour ${ }^{\mathrm{c}}$, Mahmoud Mirzaei $^{\mathrm{d}, *}$ \\ a Department of Pharmaceutical Chemistry, Faculty of Pharmaceutical Chemistry, Pharmaceutical Sciences Branch, Islamic Azad University, Tehran, Iran \\ ${ }^{\mathrm{b}}$ Department of Physics, Faculty of Science, Bilkent University, Ankara, Turkey \\ ${ }^{c}$ Department of Chemistry, Faculty of Science, Tarbiat Modares University, Tehran, Iran \\ d Bioinformatics Research Center, School of Pharmacy and Pharmaceutical Sciences, Isfahan University of Medical Sciences, Isfahan, Iran
}

\section{A R T I C L E I N F O}

\section{Article history:}

Received 2 March 2016

Received in revised form 19 April 2016

Accepted 21 April 2016

Available online 25 April 2016

Communicated by Z. Siwy

\section{Keywords:}

Silicon carbide

Fullerene

Fluorouracil

Density functional theory

\begin{abstract}
A B S T R A C T
Decorations of silicon carbide ( $\mathrm{SiC}$ ) fullerene-like nanoparticles by fluorouracil (FU) and its tautomers are investigated through density functional theory (DFT) calculations. Two models of fullerene-like particles including $\mathrm{Si}_{12} \mathrm{C}_{8}$ and $\mathrm{Si}_{8} \mathrm{C}_{12}$ are constructed to be counterparts of decorated hybrid structures, $\mathrm{FU} @ \mathrm{Si}_{12} \mathrm{C}_{8}$ and $\mathrm{FU} @ \mathrm{Si}_{8} \mathrm{C}_{12}$, respectively. The initial models including original $\mathrm{FU}$ and tautomeric structures and $\mathrm{SiC}$ nanoparticles are individually optimized and then combined for further optimizations in the hybrid forms. Covalent bonds are observed for FU@ $\mathrm{Si}_{12} \mathrm{C}_{8}$ hybrids, whereas non-covalent interactions are seen for $\mathrm{FU}_{\mathrm{S}} \mathrm{Si}_{8} \mathrm{C}_{12}$ ones. The obtained properties indicated that $\mathrm{Si}_{12} \mathrm{C}_{8}$ model could be considered as a better counterpart for interactions with $\mathrm{FU}$ structures than $\mathrm{Si}_{8} \mathrm{C}_{12}$ model. The results also showed significant effects of interactions on the properties of atoms close to the interacting regions in nanoparticles. Finally, the tautomeric structures show different behaviors in interactions with SiC nanoparticles, in which the $\mathrm{SiC}$ nanoparticles could be employed to detect the situations of tautomeric processes for FU structures.
\end{abstract}

(c) 2016 Elsevier B.V. All rights reserved.

\section{Introduction}

Fluorouracil (or 5-fluorouracil, FU) has been used as an anticancer drug to treat various types of cancers for several years [1]. The advantages of this drug have still kept it useful for medical treatments of patients, but on the other hand, too many side effects are arisen for its users [2]. Therefore, considerable efforts have been dedicated to recognize various aspects of this drug and the method to increase its safety for patients for many years $[3,4]$. By the introduction of nanotechnologies, combinations of nanostructures with FU derivatives are proposed to be helpful for medical purposes [5-8]. Researchers of various fields have drastically explored other novel materials in addition to pioneering fullerenes and carbon nanotubes [9,10]. As a result, several types of nanostructures are now recognized including nanoparticles [11], nanocones [12], nanorods [13], nanorings [14], graphenes [15], and some other types. The results also indicated the possibilities of existence of non-carbon nanostructures, which could show polarities versus non-polar carbon nanostructures [16,17]. Stabilities and properties of silicon carbide $(\mathrm{SiC})$ nanostructures have been investigated computationally and experimentally [18-20]. Earlier

\footnotetext{
* Corresponding author. Fax: +98 3136680011.

E-mail address: mdmirzaei@pharm.mui.ac.ir (M. Mirzaei).
}

researches demonstrated that both carbon and non-carbon nanostructures could be physically or chemically decorated by other atoms and molecules to make new hybrid systems with new properties [21-23]. Among Those, biologically related decorations of nanostructures could be expected to make more useful compounds for applications in life sciences and technologies [24]. Within this research, we investigated decorations of two representative SiC fullerene-like nanoparticles by FU species to construct SiC-FU hybrids (Fig. 1) through quantum computations. In addition to the original di-keto form, we also considered other ketoenol and di-enol tautomeric structures of FU for decorations of $\mathrm{SiC}$ nanoparticles. The tautomeric structures could lead to mutations in biological systems; therefore, they are important to be carefully examined for organic and bioorganic compounds [25]. Our obtained results revealed that different situations of decorated systems depend on tautomeric structures and combined SiC nanoparticles.

\section{Computational details}

Density functional theory (DFT) calculations are performed to employ the B3LYP exchange-correlation functional and the 6-31G* standard basis set as implemented in the Gaussian 98 program [26]. The models include the original di-keto, tautomeric ketoenol, di-enol forms of FU and two models of SiC fullerene-like 
(A)

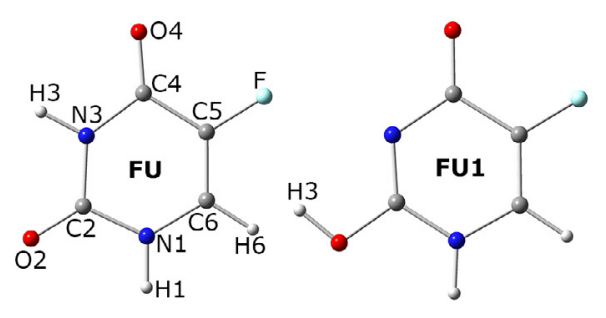<smiles>CC1=C(C)C(C)C(C)CC1C</smiles>

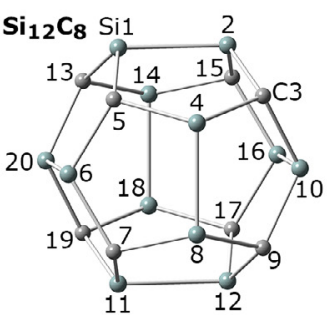<smiles>CC1CC(CO)CC(C)C1C</smiles><smiles>CC1CC(C)C(C)C(CO)C1C</smiles>

(B)
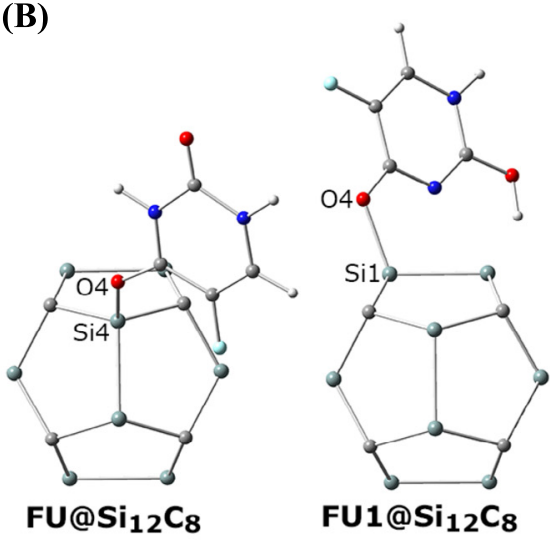

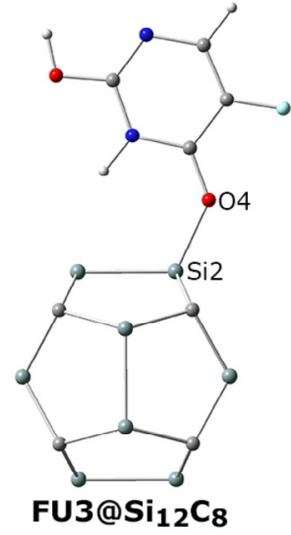

FU2@Si ${ }_{12} \mathrm{C}_{8}$

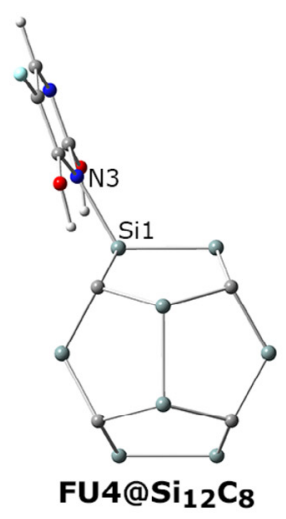

(C)

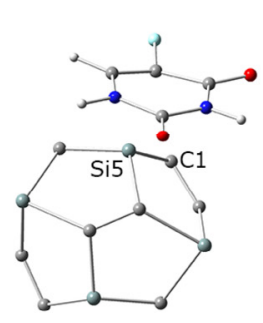

FU@Sis $\mathrm{C}_{12}$
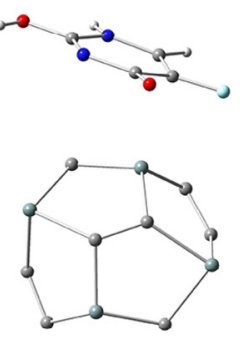

FU1@Si $\mathrm{C}_{12}$

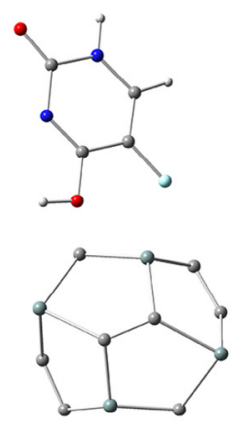

FU2@Sis $\mathrm{C}_{12}$

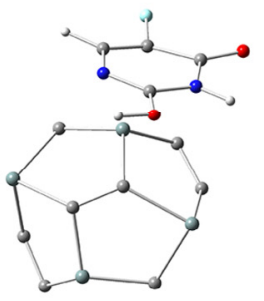

FU3@Si $\mathrm{C}_{12}$
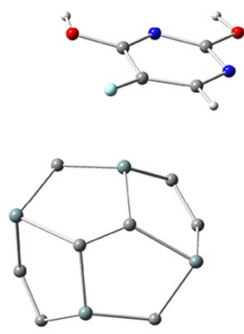

FU4@Si $\mathrm{C}_{12}$
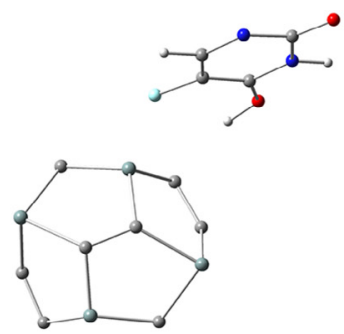

FU5@Si $\mathrm{C}_{12}$

Fig. 1. (A) Individual structures of original and tautomers of FU and also individual SiC fullerene-like nanoparticles. (B) FU@Si ${ }_{12} C_{8}$ hybrids. (C) FU@Si $C_{12}$ hybrids.

nanoparticles (Fig. 1, panel A). The hydrogen atoms were moved to other proper atomic positions in the FU structure to make ketoenol and di-enol tautomers [27]. To construct the SiC fullerene-like nanoparticles, two systems with twenty atoms for each one, $\mathrm{Si}_{12} \mathrm{C}_{8}$ and $\mathrm{Si}_{8} \mathrm{C}_{12}$, were constructed based on the presence of $\mathrm{Si}-\mathrm{Si}$ and $\mathrm{C}-\mathrm{C}$ direct bonds. After constructing the initial models, all individual models were optimized to their minimum-energy levels. Subsequently, the original and tautomeric FU structures were allowed to relax on the surface of each pre-optimized SiC nanoparticles and construct the FU-decorated SiC hybrids (FU@SiC) (Fig. 1, panels B and $\mathrm{C}$ ). The optimization processes yielded molecular properties (Table 1); dipole moments and various types of energies includ- ing total energies, binding energies, and energies for the highest occupied molecular orbitals (HOMO) and the lowest unoccupied ones (LUMO). To evaluate binding energies, differences of energies for hybrid structure and singular counterparts are employed; $E_{\mathrm{B}}=E_{\mathrm{FU} @ \mathrm{SiC}}-E_{\mathrm{FU}}-E_{\mathrm{SiC}}$. It is notes that the basis set superposition error (BSSE) [28] has been corrected for non-covalent interacting FU@SiC hybrids. To evaluate energy gaps, differences of HOMO and LUMO states are employed; $E_{\mathrm{G}}=E_{\mathrm{LUMO}}-E_{\mathrm{HOMO}}$. Additionally, atomic scale properties were determined by evaluations of chemical shifts $(\delta)$ for all atoms of the optimized structures. It is known that the chemical structures of materials could be efficiently detected by nuclear magnetic resonance (NMR) spectroscopy as a 
Table 1

Optimized molecular properties ${ }^{\mathrm{a}}$.

\begin{tabular}{|c|c|c|c|c|c|c|}
\hline Structure & $E_{\mathrm{T}} / \mathrm{eV}$ & $E_{\mathrm{B}} / \mathrm{eV}$ & $E_{\text {Hомо }} / \mathrm{eV}$ & $E_{\text {LUMO }} / \mathrm{eV}$ & $E_{\mathrm{G}} / \mathrm{eV}$ & $D_{\mathrm{M}} /$ Debye \\
\hline FU & -13987.945 & - & -6.786 & -1.378 & 5.408 & 3.903 \\
\hline FU1 & -13987.113 & - & -6.617 & -0.870 & 5.747 & 6.658 \\
\hline FU2 & -13987.329 & - & -6.518 & -1.506 & 5.012 & 3.475 \\
\hline FU3 & -13987.481 & - & -6.494 & -1.189 & 5.305 & 4.088 \\
\hline FU4 & -13987.271 & - & -6.718 & -1.099 & 5.619 & 2.530 \\
\hline FU5 & -13986.995 & - & -6.360 & -1.585 & 4.775 & 5.805 \\
\hline $\mathrm{Si}_{12} \mathrm{C}_{8}$ & -102815.599 & - & -4.741 & -3.756 & 0.985 & 0.032 \\
\hline $\mathrm{Si}_{8} \mathrm{C}_{12}$ & -75450.956 & - & -5.502 & -4.135 & 1.367 & 3.056 \\
\hline $\mathrm{FU} @ \mathrm{Si}_{12} \mathrm{C}_{8}$ & -116804.536 & $-0.992 \mathrm{C}$ & -3.941 & -3.316 & 0.652 & 10.783 \\
\hline FU1@Si ${ }_{12} C_{8}$ & -116804.172 & $-1.302 \mathrm{C}$ & -3.845 & -3.113 & 0.732 & 12.761 \\
\hline FU2@Si ${ }_{12} C_{8}$ & -116805.824 & $-3.230 \mathrm{C}$ & -4.635 & -3.652 & 0.983 & 2.749 \\
\hline FU3@Si ${ }_{12} C_{8}$ & -116804.333 & $-1.620 \mathrm{C}$ & -4.119 & -3.214 & 0.905 & 9.842 \\
\hline FU4@@Si ${ }_{12} C_{8}$ & -116804.489 & $-1.409 \mathrm{C}$ & -4.548 & -3.762 & 0.786 & 1.753 \\
\hline FU5@Si ${ }_{12} C_{8}$ & -116802.565 & $-0.128 \mathrm{nC}$ & -4.859 & -3.904 & 0.955 & 5.321 \\
\hline FU@Si ${ }_{8} C_{12}$ & -89438.916 & $-0.188 \mathrm{nC}$ & -5.241 & -3.888 & 1.353 & 5.861 \\
\hline $\mathrm{FU} 1 @ \mathrm{Si}_{8} \mathrm{C}_{12}$ & -89438.149 & $-0.146 \mathrm{nC}$ & -5.273 & -3.901 & 1.372 & 5.276 \\
\hline FU2@Si $8 C_{12}$ & -89438.385 & $-0.133 \mathrm{nC}$ & -5.266 & -3.907 & 1.359 & 5.879 \\
\hline FU3@Si $\mathrm{C}_{8} \mathrm{C}_{12}$ & -89438.493 & $-0.200 \mathrm{nC}$ & -5.140 & -3.789 & 1.351 & 8.724 \\
\hline $\mathrm{FU}_{4} @ \mathrm{Si}_{8} \mathrm{C}_{12}$ & -89438.247 & $-0.083 \mathrm{nC}$ & -5.232 & -3.865 & 1.367 & 4.913 \\
\hline FU5@Si $\mathrm{C}_{12}$ & -89438.020 & $-0.175 \mathrm{nC}$ & -5.547 & -4.194 & 1.353 & 2.253 \\
\hline
\end{tabular}

a The structures are shown in Fig. 1. The characters $C$ and $\mathrm{nC}$ besides binding energies indicate covalent and non-covalent interactions between FU and SiC counterparts. The results for individual FU are comparable with Ref. [27].

versatile technique among the characterizing techniques [29]. To evaluate $\delta$ values, chemical shielding tensors $\left(\sigma_{\text {ii }}\right)$ were computed based on the gauge-included atomic orbital (GIAO) approach and then converted to isotropic chemical shieldings $\left(\sigma_{\text {iso }}\right)$ through the equation: $\sigma_{\text {iso }}(\mathrm{ppm})=\left(\sigma_{11}+\sigma_{22}+\sigma_{33}\right) / 3$ [30]. Subsequently, the obtained $\sigma_{\text {iso }}$ values were converted to $\delta$ values using the references of tetramethylsilan (TMS) for $\mathrm{Si}, \mathrm{C}$, and $\mathrm{H}$ atoms, water $\left(\mathrm{H}_{2} \mathrm{O}\right)$ for $\mathrm{O}$ atoms, and ammonia $\left(\mathrm{NH}_{3}\right)$ for $\mathrm{N}$ atoms in the equation $\delta(\mathrm{ppm})=\sigma_{\text {iso, Reference }}-\sigma_{\text {iso,Sample [29]. The chemical shield- }}$ ings originated from the electronic sites of atoms, could reveal insightful information about the electronic properties of structures $[30,31]$.

\section{Results and discussion}

\subsection{Optimized molecular properties}

Optimized molecular properties including total energies $\left(E_{\mathrm{T}}\right)$, binding energies $\left(E_{\mathrm{B}}\right)$, energies of the highest occupied molecular orbitals and the lowest unoccupied molecular orbitals ( $E_{\text {HOMO }}$ and $\left.E_{\text {LUMO }}\right)$, and dipole moments $\left(D_{\mathrm{M}}\right)$ for the individual and hybrid models of this work (Fig. 1) are listed in Table 1. The individual models are the original and tautomeric forms of FU and two models of $\mathrm{SiC}$ fullerene-like nanoparticles include $\mathrm{Si}_{12} \mathrm{C}_{8}$ and $\mathrm{Si}_{8} \mathrm{C}_{12}$. The criterion of making two nanoparticles is to consider existence of $\mathrm{Si}-\mathrm{Si}$ bond in the $\mathrm{Si}_{12} \mathrm{C}_{8}$ model and $\mathrm{C}-\mathrm{C}$ bond in the $\mathrm{Si}_{8} \mathrm{C}_{12}$ one as well as $\mathrm{Si}-\mathrm{C}$ bond in both models. The tautomeric structures are constructed based on movement of $\mathrm{H}$ atoms among $\mathrm{N}_{1}$, $\mathrm{N}_{3}, \mathrm{O}_{2}$, and $\mathrm{O}_{4}$ atomic positions. The hybrid structures are constructed through decorations of $\mathrm{Si}_{12} \mathrm{C}_{8}$ and $\mathrm{Si}_{8} \mathrm{C}_{12}$ nanoparticles by the available FU structures to make FU@SiC hybrids (Fig. 1, panels $B$ and $C$ ). The results of optimized energies indicate that the most stable structure is the original di-keto form of FU and the most unstable structure is $\mathrm{FU}_{5}$, a keto-enol form with movement of $\mathrm{H}_{1}$ to $\mathrm{O}_{4}$ atomic position. Comparing the results of total energies indicates that the stabilities for other tautomers are ordered as $\mathrm{FU}_{3}>$ $\mathrm{FU}_{2}>\mathrm{FU}_{4}>\mathrm{FU}_{1}$. The results are in agreement with earlier results on uracil and FU tautomeric structures [27]. The results for $E_{\text {HOMO }}$ and $E_{\mathrm{LUMO}}$ also demonstrated that the orbital levels and the gaps between them are changed due to tautomerizations, in which the results reveal the changes of electronic properties for molecular systems of tautomers. Different magnitudes for $E_{\text {HOMO }}$ and $E_{\text {LUMO }}$ are seen for the $\mathrm{SiC}$ nanoparticles and different gaps are also seen for the two structures based on their atomic components. Different magnitudes for dipole moments are also obvious for the individual tautomers and also for two $\mathrm{SiC}$ nanoparticles, in which the value of $D_{M}$ for $\mathrm{Si}_{8} \mathrm{C}_{12}$ is larger than $\mathrm{Si}_{12} \mathrm{C}_{8}$ structure.

There are two sets of FU@SiC hybrids based on the components of $\mathrm{SiC}$ nanoparticles; $\mathrm{Si}_{12} \mathrm{C}_{8}$ and $\mathrm{Si}_{8} \mathrm{C}_{12}$. A quick look at the $\mathrm{B}$ and $\mathrm{C}$ panels of Fig. 1 indicates that the situations of interactions are different for the FU tautomers on the surface of two SiC nanoparticles. After optimizations, covalent attachments are seen for the $\mathrm{Si}_{12} \mathrm{C}_{8}$ nanoparticles, whereas only non-covalent interactions are seen for the $\mathrm{Si}_{8} \mathrm{C}_{12}$ nanoparticles. The trend shows the importance of atomic components in the structural behaviors of molecular interactions. Comparing the values of $E_{\mathrm{T}}$ for $\mathrm{FU}_{\mathrm{SS}}{ }_{12} \mathrm{C}_{8}$ and $\mathrm{FU} @ \mathrm{Si}_{8} \mathrm{C}_{12}$ hybrids indicates that the stabilities are different for the two hybrid systems, in which stronger interactions are seen for the FU@Si ${ }_{12} \mathrm{C}_{8}$ hybrids in panel B of Fig. 1 rather than the FU@Si $\mathrm{C}_{12}$ hybrids in panel C. The results for FU@Si ${ }_{12} \mathrm{C}_{8}$ hybrids indicate that the obtained stabilities are different for the hybrid structures as could be seen by the magnitudes of $E_{\mathrm{T}}$, in which the most stable hybrid structure is $\mathrm{FU}_{2} @ \mathrm{Si}_{12} \mathrm{C}_{8}$ among the investigated hybrids. Interestingly, the $\mathrm{H}$ atom of $\mathrm{O}_{4}$ is moved to $\mathrm{Si}_{1}$ atom of $\mathrm{SiC}$ nanoparticle and also the covalent attachment is seen for $\mathrm{N}_{3}$ and $\mathrm{Si}_{2}$ atom in the hybrid structure. With the exception of $\mathrm{FU}_{5} @ \mathrm{Si}_{12} \mathrm{C}_{8}$, all other hybrids in this set include covalent bonds with almost similar strengths. However, physical interactions are only seen for $\mathrm{FU}_{5} @ \mathrm{Si}_{12} \mathrm{C}_{8}$ and the results of $E_{\mathrm{T}}$ show the least stability for this structure among available hybrids. As it was shown earlier, the results of $E_{\mathrm{T}}$ for individual tautomers indicated $\mathrm{FU}_{5}$ is the least stable structure, in which the same result is also detected for $\mathrm{FU}_{5} @ \mathrm{Si}_{12} \mathrm{C}_{8}$ hybrid. However, the stability for the original FU structure in the hybrid form is lowered in comparison with the original individual FU structure. Due to the special properties of $\mathrm{Si}_{12} \mathrm{C}_{8}$ nanoparticle, the stability for $\mathrm{FU}_{2}$ is increased in the $\mathrm{FU}_{2} @ \mathrm{Si}_{12} \mathrm{C}_{8}$ hybrid. Magnitudes of $E_{\mathrm{B}}$ also approve the values of stabilities, in which the most stable structure is $\mathrm{FU}_{2} @ \mathrm{Si}_{12} \mathrm{C}_{8}$ and the least stable structure is $\mathrm{FU}_{5} @ \mathrm{Si}_{12} \mathrm{C}_{8}$. The stabilities for other FU@Si ${ }_{12} \mathrm{C}_{8}$ hybrids are almost similar. Different magnitudes for energies of HOMO and LUMO levels and also their gaps were observed for the hybrid structures, meaning changes of electronic properties of molecular orbitals of the investigated structures. The values of $D_{\mathrm{M}}$ indicate that the polarities are significantly changed during the hybridizations, in which remarkable magnitudes are seen for FU 1 , FU@, and FU $\mathrm{FU}_{3} @ \mathrm{Si} 12 \mathrm{C} 8$ 
Table 2

Atomic chemical shifts $(\delta / \mathrm{ppm})$ for FU species ${ }^{\mathrm{a}}$.

\begin{tabular}{|c|c|c|c|c|c|c|}
\hline Atom & FU@ & FU1@ & FU2@ & FU3@ & FU4@ & FU5@ \\
\hline \multirow[t]{3}{*}{$\mathrm{H}_{1}$} & 4.995 & 5.439 & 5.780 & 4.986 & 5.017 & 4.976 \\
\hline & $(5.906)$ & $(6.446)$ & (5.182) & $(5.886)$ & (12.822) & (5.189) \\
\hline & [6.225] & [6.027] & [5.935] & [5.952] & [5.834] & [7.074] \\
\hline \multirow[t]{3}{*}{$\mathrm{H}_{3}$} & 6.078 & 4.791 & 5.325 & 6.806 & 4.776 & 6.083 \\
\hline & (7.167) & (7.755) & (5.595) & (15.732) & (16.819) & (6.156) \\
\hline & [6.619] & [5.282] & [5.840] & [7.499] & [5.533] & [6.253] \\
\hline \multirow[t]{3}{*}{$\mathrm{H}_{6}$} & 6.382 & 6.215 & 6.664 & 7.072 & 7.899 & 8.163 \\
\hline & (6.578) & (6.624) & (6.368) & (7.943) & (8.133) & (8.249) \\
\hline & [8.062] & [7.124] & [6.969] & [8.502] & [8.809] & [8.443] \\
\hline \multirow[t]{3}{*}{$C_{2}$} & 136.627 & 142.291 & 139.971 & 142.662 & 151.906 & 140.097 \\
\hline & (134.621) & (144.275) & (140.678) & (142.637) & (150.228) & (140.180) \\
\hline & [135.529] & [144.466] & [139.029] & [149.689] & [155.634] & [140.189] \\
\hline \multirow[t]{3}{*}{$\mathrm{C}_{4}$} & 146.779 & 151.802 & 153.592 & 143.802 & 149.995 & 143.254 \\
\hline & (160.498) & (154.796) & (154.613) & (150.177) & (155.099) & (143.748) \\
\hline & [146.776] & [149.459] & [150.775] & [144.805] & [154.424] & [143.387] \\
\hline \multirow[t]{3}{*}{$C_{5}$} & 136.895 & 143.568 & 129.162 & 143.432 & 135.706 & 126.438 \\
\hline & (136.348) & (139.437) & (135.406) & (140.461) & (136.077) & (125.979) \\
\hline & [124.781] & [138.386] & [132.313] & [133.408] & [129.173] & [136.944] \\
\hline \multirow[t]{3}{*}{$\mathrm{C}_{6}$} & 117.069 & 111.918 & 122.796 & 130.951 & 142.045 & 147.789 \\
\hline & (123.377) & (114.706) & (117.356) & (141.124) & (143.544) & (148.463) \\
\hline & [137.046] & [125.641] & [125.324] & [149.874] & [148.893] & [146.812] \\
\hline \multirow[t]{3}{*}{$\mathrm{N}_{1}$} & 113.702 & 100.533 & 136.860 & 185.268 & 237.755 & 240.960 \\
\hline & (130.549) & (118.372) & (117.586) & (215.294) & (230.848) & (241.019) \\
\hline & [134.089] & [110.321] & [139.704] & [199.828] & [246.889] & [238.571] \\
\hline \multirow[t]{3}{*}{$\mathrm{N}_{3}$} & 156.102 & 220.437 & 226.799 & 150.767 & 213.058 & 136.042 \\
\hline & (157.998) & (233.683) & (168.429) & (154.119) & $(162.900)$ & (136.741) \\
\hline & [154.613] & [225.434] & [227.906] & [155.032] & [212.268] & [139.109] \\
\hline \multirow[t]{3}{*}{$\mathrm{O}_{2}$} & 287.284 & 119.704 & 312.088 & 120.142 & 134.512 & 301.441 \\
\hline & $(300.942)$ & (137.276) & (312.897) & (127.032) & (181.156) & (300.135) \\
\hline & [309.969] & [126.647] & [296.703] & [136.121] & [148.729] & [114.628] \\
\hline \multirow[t]{3}{*}{$\mathrm{O}_{4}$} & 257.208 & 205.977 & 135.973 & 290.683 & 117.923 & 92.839 \\
\hline & (239.329) & (232.281) & $(246.053)$ & (185.180) & (187.226) & (99.819) \\
\hline & [228.632] & [177.710] & [132.936] & [249.089] & [131.516] & [286.319] \\
\hline \multirow[t]{3}{*}{$\mathrm{F}$} & 50.037 & 63.269 & 42.277 & 57.608 & 46.768 & 10.490 \\
\hline & (68.604) & (64.739) & $(48.723)$ & $(61.462)$ & (53.738) & (18.268) \\
\hline & [38.816] & [57.746] & [41.247] & [46.412] & [38.939] & [33.169] \\
\hline
\end{tabular}

a The structures are shown in Fig. 1. The results for individual FU are comparable with Ref. [27]. In each column, the free number belongs to individual structure, the number in parenthesis belongs to FU@Si ${ }_{12} \mathrm{C}_{8}$ hybrids, and the number in brackets belongs to FU@Si ${ }_{8} \mathrm{C}_{12}$ hybrids.

hybrids. As mentioned earlier, the interactions between FU tautomers and $\mathrm{Si}_{8} \mathrm{C}_{12}$ nanoparticles are all non-covalent (Fig. 1, panel $\mathrm{C})$, in which the stabilities of $\mathrm{FU}_{\mathrm{S}} \mathrm{Si}_{8} \mathrm{C}_{12}$ are lower than the stabilities of $\mathrm{FU}_{\mathrm{S}} \mathrm{Si}_{12} \mathrm{C}_{8}$ hybrids. Among the $\mathrm{FU} @ \mathrm{Si}_{8} \mathrm{C}_{12}$ hybrids, the most stable structure is seen for the original $\mathrm{FU}$ on the $\mathrm{Si}_{8} \mathrm{C}_{12}$ nanoparticle. The results of $E_{\mathrm{B}}$ also approve that the interaction between $\mathrm{FU}$ and $\mathrm{Si}_{8} \mathrm{C}_{12}$ nanoparticle is stronger than other hybrid structures of $\mathrm{FU}_{1}-\mathrm{FU}_{5} @ \mathrm{Si}_{8} \mathrm{C}_{12}$. The stabilities and interaction strengths are almost similar for other hybrid structures. The levels for HOMO and LUMO still detect the effects of hybridizations in the $\mathrm{FU}_{\mathrm{SSi}} \mathrm{C}_{12}$ hybrids but the magnitudes of gaps are larger in comparison with the FU@ $\mathrm{Si}_{12} \mathrm{C}_{8}$ hybrids. However, the magnitudes of $D_{\mathrm{M}}$ for $\mathrm{FU} @ \mathrm{Si}_{8} \mathrm{C}_{12}$ hybrids are smaller than FU@Si ${ }_{12} \mathrm{C}_{8}$ ones. Comparing the results for individual $\mathrm{SiC}$ nanoparticles and hybrids, reveals the influence of functionalizations on the properties of nanoparticles, in which the magnitudes of $D_{\mathrm{M}}$ for individual nanoparticles were significantly changed in the hybrid structures. As a remarkable conclusion, it could be mentioned that the existence of $\mathrm{Si}-\mathrm{Si}$ bonds in $\mathrm{SiC}$ nanoparticles make the formation of covalent bonds possible for FU tautomers, whereas the existence of $\mathrm{C}-\mathrm{C}$ bonds only show possibilities for formation of non-covalent interactions. In a very recent work [32], adsorption studies of FU at the surface of original and doped $C_{60}$ fullerene nanostructures indicated that the interactions are non-covalent for original $\mathrm{C}_{60}$ whereas covalent interactions are observed for doped $\mathrm{C}_{60} \mathrm{~S}$. In another work [27], the tautomeric structures of FU contribute to non-covalent interactions with original silicon sheets. These results and the results of current research could indicate that the heterogeneous nanostructures show better tendency to interact with FU structures in comparison with original nanostructures. The type of heterogeneous nanostructure is also important, in which the interactions of $\mathrm{FU}$ with $\mathrm{Si}_{8} \mathrm{C}_{12}$ are all non-covalent comparing with $\mathrm{Si}_{12} \mathrm{C}_{8}$ nanostructure.

\subsection{Atomic chemical shifts}

The evaluated chemical shifts $(\delta)$ for the atoms of optimized individual and hybrid structures of FU, SiC, and FU@SiC (Fig. 1) are listed in Tables 2-4. The chemical shielding $(\sigma)$ tensors are originated from the electronic sites of atoms; therefore, they could reveal insightful information about the electronic properties of matters [29]. A quick look at the results for atoms of FU counterparts (Table 2) in both individual and hybrid forms indicates that the electronic environment for each atom is changed from the original structure to tautomer or from individual structure to hybrid forms. Moreover, each atom of FU structure detects a different environment in two hybrid systems, based on different components of $\mathrm{SiC}$ fullerene-like particles. Two $\mathrm{H}$ atoms of $\mathrm{FU}, \mathrm{H}_{1}$ and $\mathrm{H}_{3}$, are moving through tautomerization processes; but the position for $\mathrm{H}_{6}$ is kept frozen. Since the magnitudes of $\delta$ show the discrepancy of electronic properties of the sample atom from the reference atom, so these magnitudes could show significant changes of electronic properties of each atom from the reference point to current situation. Although the position of $\mathrm{H}_{6}$ is kept frozen through tautomers, the electronic properties are still changed in different structures due to indirect side effects, as could be seen by the magnitudes of $\delta$. In all cases, the effects for $\mathrm{H}_{6}$ atoms of $\mathrm{FU} @ \mathrm{Si}_{8} \mathrm{C}_{12}$ are much more significant than the other hybrid and individual structures. 
Table 3

Atomic chemical shifts $(\delta / \mathrm{ppm})$ for $\mathrm{Si}_{12} \mathrm{C}_{8}$ fullerene-like nanoparticles ${ }^{\mathrm{a}}$.

\begin{tabular}{|c|c|c|c|c|c|c|c|}
\hline Atom & Individual & FU@ & FU1@ & FU2@ & FU3@ & FU4@ & FU5@ \\
\hline $\mathrm{Si}_{1}$ & 408.569 & 365.038 & 102.839 & 48.725 & 42.657 & 180.863 & 360.514 \\
\hline $\mathrm{Si}_{2}$ & 407.044 & 318.628 & 188.457 & 22.520 & 117.825 & 215.926 & 395.336 \\
\hline $\mathrm{Si}_{4}$ & 414.081 & 120.6949 & 411.389 & 396.223 & 393.728 & 410.542 & 413.469 \\
\hline $\mathrm{Si}_{6}$ & 413.793 & 406.252 & 374.864 & 362.364 & 386.881 & 376.509 & 404.659 \\
\hline $\mathrm{Si}_{8}$ & 413.883 & 201.790 & 385.899 & 382.337 & 385.204 & 393.673 & 407.878 \\
\hline $\mathrm{Si}_{10}$ & 412.404 & 389.504 & 355.536 & 352.660 & 369.679 & 388.532 & 408.777 \\
\hline $\mathrm{Si}_{11}$ & 407.433 & 372.346 & 377.234 & 144.527 & 105.776 & 349.269 & 394.081 \\
\hline $\mathrm{Si}_{12}$ & 406.456 & 406.548 & 124.476 & 208.131 & 329.246 & 401.831 & 366.396 \\
\hline $\mathrm{Si}_{14}$ & 413.883 & 338.765 & 365.960 & 403.791 & 394.030 & 392.047 & 409.662 \\
\hline $\mathrm{Si}_{16}$ & 411.931 & 357.869 & 410.318 & 356.101 & 365.290 & 391.467 & 412.858 \\
\hline $\mathrm{Si}_{18}$ & 413.059 & 81.291 & 384.708 & 379.759 & 384.263 & 407.747 & 413.242 \\
\hline $\mathrm{Si}_{20}$ & 410.065 & 370.899 & 280.675 & 381.705 & 391.468 & 371.745 & 400.820 \\
\hline $\mathrm{C}_{3}$ & 123.991 & 113.729 & 111.581 & 170.655 & 141.639 & 72.408 & 119.365 \\
\hline$C_{5}$ & 126.333 & 127.636 & 154.641 & 187.161 & 121.404 & 55.756 & 136.137 \\
\hline$C_{7}$ & 126.421 & 123.072 & 143.402 & 137.286 & 123.777 & 113.249 & 128.134 \\
\hline $\mathrm{C}_{9}$ & 123.991 & 94.284 & 143.253 & 143.123 & 125.975 & 161.987 & 125.624 \\
\hline $\mathrm{C}_{13}$ & 125.603 & 135.439 & 91.897 & 186.083 & 120.421 & 84.048 & 128.339 \\
\hline $\mathrm{C}_{15}$ & 123.144 & 127.885 & 124.988 & 177.736 & 141.918 & 85.321 & 113.929 \\
\hline $\mathrm{C}_{17}$ & 125.603 & 121.524 & 119.160 & 143.390 & 152.283 & 178.631 & 124.181 \\
\hline $\mathrm{C}_{19}$ & 123.144 & 146.383 & 115.894 & 137.168 & 122.817 & 109.176 & 128.889 \\
\hline
\end{tabular}

a The structures are shown in Fig. 1. The structures indicated by FU@ imply for the properties of $\mathrm{Si}_{12} \mathrm{C}_{8}$ in $\mathrm{FU}_{\mathrm{S}} @ \mathrm{Si}_{12} \mathrm{C}_{8}$ hybrids (Fig. 1, panel B).

Table 4

Atomic chemical shifts $(\delta / \mathrm{ppm})$ for $\mathrm{Si}_{8} \mathrm{C}_{12}$ nanoparticles ${ }^{\mathrm{a}}$.

\begin{tabular}{|c|c|c|c|c|c|c|c|}
\hline Atom & Individual & FU@ & FU1@ & FU2@ & FU3@ & FU4@ & FU5@ \\
\hline $\mathrm{Si}_{3}$ & 2.157 & 5.279 & 0.489 & 0.0567 & 8.334 & 5.451 & 4.733 \\
\hline $\mathrm{Si}_{5}$ & 232.811 & 277.643 & 354.226 & 373.269 & 296.581 & 373.330 & 297.163 \\
\hline $\mathrm{Si}_{7}$ & 342.473 & 356.042 & 340.057 & 347.788 & 354.738 & 346.907 & 326.439 \\
\hline $\mathrm{Si}_{9}$ & 233.433 & 297.236 & 245.538 & 266.704 & 285.973 & 270.142 & 258.055 \\
\hline $\mathrm{Si}_{13}$ & 344.484 & 296.434 & -312.628 & 313.691 & 306.282 & 310.871 & 290.416 \\
\hline $\mathrm{Si}_{15}$ & 233.489 & 289.726 & 279.468 & 270.884 & 280.474 & 275.685 & 270.463 \\
\hline $\mathrm{Si}_{17}$ & 345.683 & 230.173 & 249.514 & 259.097 & 230.511 & 270.165 & 247.346 \\
\hline $\mathrm{Si}_{19}$ & 292.918 & 166.026 & 216.477 & 209.326 & 174.927 & 207.272 & 199.459 \\
\hline$C_{1}$ & 128.417 & 127.309 & 126.709 & 127.408 & 129.252 & 129.039 & 136.177 \\
\hline $\mathrm{C}_{2}$ & 121.377 & 101.589 & 105.286 & 108.689 & 108.175 & 111.786 & 91.379 \\
\hline $\mathrm{C}_{4}$ & 120.772 & 117.892 & 121.579 & 118.861 & 121.084 & 121.166 & 121.337 \\
\hline $\mathrm{C}_{6}$ & 129.845 & 160.748 & 151.017 & 146.359 & 156.411 & 148.175 & 143.191 \\
\hline $\mathrm{C}_{8}$ & 128.571 & 129.929 & 134.298 & 133.192 & 130.456 & 133.672 & 129.338 \\
\hline$C_{10}$ & 121.377 & 119.294 & 119.324 & 119.141 & 124.637 & 120.959 & 141.273 \\
\hline $\mathrm{C}_{11}$ & 97.843 & 113.136 & 113.573 & 108.248 & 110.372 & 106.466 & 112.187 \\
\hline $\mathrm{C}_{12}$ & 129.759 & 122.139 & 124.479 & 122.317 & 122.727 & 125.806 & 124.239 \\
\hline $\mathrm{C}_{14}$ & 129.420 & 147.876 & 138.156 & 139.861 & 145.776 & 141.019 & 138.428 \\
\hline $\mathrm{C}_{16}$ & 128.663 & 132.075 & 138.867 & 131.875 & 137.516 & 135.543 & 141.649 \\
\hline $\mathrm{C}_{18}$ & 98.349 & 105.893 & 106.361 & 102.949 & 106.118 & 106.631 & 115.506 \\
\hline $\mathrm{C}_{20}$ & 98.726 & 73.774 & 74.893 & 83.106 & 79.786 & 85.087 & 81.361 \\
\hline
\end{tabular}

a The structures are shown in Fig. 1. The structures indicated by FU@ imply for the properties of $\mathrm{Si}_{8} \mathrm{C}_{12}$ in $\mathrm{FU}_{\mathrm{S}} @ \mathrm{Si}_{8} \mathrm{C}_{12}$ hybrids (Fig. 1, panel C).

However, a clear harmony of changes are not seen for $\mathrm{H}_{1}$ and $\mathrm{H}_{3}$ atoms, which are moving through nitrogen and oxygen atomic sites. Interestingly, $\mathrm{H}_{3}$ from $\mathrm{O}_{4}$ is moved to $\mathrm{Si}_{1}$ atomic site in $\mathrm{FU}_{2} @ \mathrm{Si}_{12} \mathrm{C}_{8}$ hybrid, which is seen as an unusual observation among the investigated model systems. The small magnitudes of $\delta$ for hydrogen atoms are due to existence of weak electronic environment for this atom in comparison with larger magnitudes for other heavier atoms.

The results of Table 2 for carbon atoms also show different electronic environments for different atomic positions. Although the carbon atoms do not directly participate in tautomerizations, they can detect effects of these processes as could be seen by their magnitudes of $\delta$. The properties for each atom among three models indicate that the changes of $\delta$ are significant due to being in different structural situations. For nitrogen atoms, many more significant effects are seen especially for that atom which is directly participated in the tautomerizations. In the original structure, both of $\mathrm{N}_{1}$ and $\mathrm{N}_{3}$ are hydrogenated, whereas in the tautomers the hydrogen atoms are removed from one or both of nitrogen atoms. Interesting observations are obtained for $\mathrm{FU}_{2} @ \mathrm{Si}_{12} \mathrm{C}_{8}$ and $\mathrm{FU}_{4} @ \mathrm{Si}_{12} \mathrm{C}_{8}$ hybrids, in which $\mathrm{N}_{3}$ is respectively connected to $\mathrm{Si}_{2}$ and $\mathrm{Si}_{1}$ atoms through covalent bonds. In comparison with individual structures, the changes of $\delta$ for $\mathrm{N}_{3}$ atoms in two hybrids also indicate that $\mathrm{FU}_{2} @ \mathrm{Si}_{12} \mathrm{C}_{8}$ and $\mathrm{FU}_{4} @ \mathrm{Si}_{12} \mathrm{C}_{8}$ are in strong interactions. It seems that the position of $\mathrm{N}_{3}$ between two types of oxygen atoms, $\mathrm{O}_{2}$ is urea type and $\mathrm{O}_{4}$ is amide type, makes it a proper atom to undergo stronger interactions in comparison with $\mathrm{N}_{1}$. The stability of $\mathrm{SiC}$ nanoparticle is also important, in which strong interactions with FU counterparts are seen with $\mathrm{Si}_{12} \mathrm{C}_{8}$ (more stability) but not with $\mathrm{Si}_{8} \mathrm{C}_{12}$ (less stability). Two oxygen atoms of urea type $\left(\mathrm{O}_{2}\right)$ and amide type $\left(\mathrm{O}_{4}\right)$ show different behaviors in the tautomeric systems and also in interaction with $\mathrm{SiC}$ nanoparticles. Parallel to the results for $\mathrm{N}_{3}$, the interaction for $\mathrm{O}_{4}$ is strong with $\mathrm{Si}_{12} \mathrm{C}_{8}$ nanoparticles especially in $\mathrm{FU}_{1} @ \mathrm{Si}_{12} \mathrm{C}_{8}$ and $\mathrm{FU}_{3} @ \mathrm{Si}_{12} \mathrm{C}_{8}$ hybrids, in which covalent bonds with $\mathrm{Si}_{1}$ and $\mathrm{Si}_{2}$ are formed. Combinations of the results for $\mathrm{N}_{3}$ and $\mathrm{O}_{4}$ could reveal that the amide part of $\mathrm{FU}$ is more proper for interactions with $\mathrm{SiC}$ nanoparticles than the urea part $\left(\mathrm{N}_{1}\right.$ and $\left.\mathrm{O}_{2}\right)$. Moreover, $\mathrm{N}_{3}$ is the winner of strong interactions, in which $\mathrm{O}_{4}$ releases its hydrogen in $\mathrm{FU}_{2} @ \mathrm{Si}_{12} \mathrm{C}_{8}$ to make better possibility of strong interactions of $\mathrm{N}_{3}$ with $\mathrm{Si}_{2}$ atoms. The 
oxygen atom has two lone pairs of electrons in the electronic site, which could be floated during the interactions to yield different properties. Similar situations of electron lone pairs are observed for the fluorine atom, in which the magnitudes of $\delta$ indicate different properties in the investigated individual and hybrid models. Since the $\mathrm{F}$ atom does not directly contribute to tautomerization, the magnitudes of changes of $\delta$ are not significant as much as nitrogen and oxygen atoms, but they are still notable. By examining the magnitudes of $\delta$ for $\mathrm{F}$ atom in $\mathrm{FU}_{5}$ and hybrids, it could be proposed that there is an intramolecular hydrogen bond interaction between $\mathrm{H}_{1}$ and $\mathrm{F}$ atoms at individual and $\mathrm{FU}_{5} @ \mathrm{Si}_{12} \mathrm{C}_{8}$ hybrid, whereas this interaction is protected in $\mathrm{FU}_{5} @ \mathrm{Si}_{8} \mathrm{C}_{12}$ hybrid. This result could be more approved by the magnitudes of $\delta$ for $\mathrm{H}_{1}$ in $\mathrm{FU}_{5}$ and related hybrids, in which the magnitude is increased in $\mathrm{FU}_{5} @ \mathrm{Si}_{8} \mathrm{C}_{12}$ in comparison with individual FU and $\mathrm{FU}_{5} @ \mathrm{Si}_{12} \mathrm{C}_{8}$ hybrid.

The obtained $\delta$ for atoms of optimized $\mathrm{Si}_{12} \mathrm{C}_{8}$ and $\mathrm{Si}_{8} \mathrm{C}_{12}$ fullerene-like nanoparticles (Fig. 1 ) in the forms of individual and hybrids are listed in Tables 3 and 4. The tautomeric structures do not similarly interact with the SiC counterparts; therefore, the results for $\mathrm{Si}_{12} \mathrm{C}_{8}$ and $\mathrm{Si}_{8} \mathrm{C}_{12}$ and also for each $\mathrm{SiC}$ counterpart in the tautomeric interacting systems are different. Comparing the atomic parameters between the individual particle and tautomeric interacting counterparts indicate that the properties are significantly highlighted for the atoms of interaction regions. Furthermore, the results of other atoms also show the effects of interactions in other atomic regions are far from the exact interaction regions. Significant effects are observed for the atoms of interaction regions in the FU@Si ${ }_{12} \mathrm{C}_{8}$ hybrids more than the $\mathrm{FU}_{0} \mathrm{Si}_{8} \mathrm{C}_{12}$ hybrids. As mentioned earlier for the optimized properties, the $\mathrm{FU}_{\mathrm{S}} \mathrm{Si}_{12} \mathrm{C}_{8}$ hybrids were seen more stable than the $\mathrm{FU}_{\mathrm{S}} \mathrm{Si}_{8} \mathrm{C}_{12}$ hybrids with respect to energies. The atomic results for the hybrids and their counterparts also show that there are proper interactions in the FU@Si ${ }_{12} \mathrm{C}_{8}$ hybrids more significant than $\mathrm{FU} @ \mathrm{Si}_{8} \mathrm{C}_{12}$ hybrids. The atomic results for individual nanoparticles also indicated different properties, which could determine their characteristics for desired applications as could be seen by different situations of interactions in the investigated hybrids.

\section{Conclusions}

Within this work, we have investigated the properties of interactions between FU tautomers and SiC fullerene-like nanoparticles through DFT calculations of molecular and atomic properties. The results indicated that the properties of FU@SiC hybrids and also for each of SiC particles are different. The energetic properties indicated that FU@Si ${ }_{12} \mathrm{C}_{8}$ hybrids are more stable than $\mathrm{FU} @ \mathrm{Si}_{8} \mathrm{C}_{12}$ hybrids, in which the atomic properties also indicated that the interactions between the counterparts of former hybrids are many more significant than the latter ones. Comparing the results for individual $\mathrm{SiC}$ particles and hybrids indicated that the most significant effects of interactions could be seen for the atoms of interaction regions, but the effects for other atoms are still notable. In the cases of FU@Si ${ }_{12} \mathrm{C}_{8}$ hybrids, formations of covalent bonds were also detected between the FU tautomers and $\mathrm{Si}_{12} \mathrm{C}_{8}$ nanoparticle, in which only non-covalent interactions were seen for FU@Si $\mathrm{C}_{12}$ hybrids. Distances between the HOMO and LUMO levels for FU@Si ${ }_{12} C_{8}$ hybrids are smaller than $\mathrm{FU}_{\mathrm{S}} \mathrm{Si}_{8} \mathrm{C}_{12}$ hybrids in agreement with the smaller distance for individual $\mathrm{Si}_{12} \mathrm{C}_{8}$ than individual $\mathrm{Si}_{8} \mathrm{C}_{12}$ particles. And finally, the stabilities and interactions of FU tautomers could be investigated by SiC fullerene-like nanoparticles, in which $\mathrm{Si}_{12} \mathrm{C}_{8}$ fullerene-like nanoparticle could be better than $\mathrm{Si}_{8} \mathrm{C}_{12}$ one.

\section{References}

[1] R. Amorim, C. Pinheiro, V. Miranda-Gonçalves, H. Pereira, M.P. Moyer, A. Preto, F. Baltazar, Monocarboxylate transport inhibition potentiates the cytotoxic effect of 5-fluorouracil in colorectal cancer cells, Cancer Lett. 365 (2015) 68-78.

[2] S.E. Mahoney, J.M. Davis, E.A. Murphy, J.L. McClellan, B. Gordon, M.M. Pena, Effects of 5-fluorouracil chemotherapy on fatigue: role of MCP-1, Brain Behav. Immun. 27 (2013) 155-161.

[3] O. Kikuchi, S. Ohashi, Y. Nakai, S. Nakagawa, K. Matsuoka, T. Kobunai, T. Takechi, Y. Amanuma, M. Yoshioka, T. Ida, Y. Yamamoto, Y. Okuno, S. Miyamoto, H. Nakagawa, K. Matsubara, T. Chiba, M. Muto, Novel 5-fluorouracil-resistant human esophageal squamous cell carcinoma cells with dihydropyrimidine dehydrogenase overexpression, Am. J. Cancer Res. 5 (2015) 2431-2440.

[4] K. Ganguly, A.R. Kulkarni, T.M. Aminabhavi, In vitro cytotoxicity and in vivo efficacy of 5-fluorouracil-loaded enteric-coated PEG-crosslinked chitosan microspheres in colorectal cancer therapy in rats, Drug Deliv. 22 (2015) 1-14.

[5] M. Schober, M.A. Javed, G. Beyer, N. Le, A. Vinci, M. Sund, A. Neesse, S. Krug, New advances in the treatment of metastatic pancreatic cancer, Digestion 92 (2015) 175-184.

[6] G. Tuncelli, A.N. Ay, B. Zümreoglu-Karan, 5-Fluorouracil intercalated iron oxide@layered double hydroxide core-shell nano-composites with isotropic and anisotropic architectures for shape-selective drug delivery applications, Mater. Sci. Eng. C, Mater. Biol. Appl. 55 (2015) 562-568.

[7] Y. Wang, D. Liu, Q. Zheng, Q. Zhao, H. Zhang, Y. Ma, J.K. Fallon, Q. Fu, M.T. Haynes, G. Lin, R. Zhang, D. Wang, X. Yang, L. Zhao, Z. He, F. Liu, Disulfide bond bridge insertion turns hydrophobic anticancer prodrugs into self-assembled nanomedicines, Nano Lett. 14 (2014) 5577-5583.

[8] M. Mirzaei, R.S. Ahangari, Formations of CNT-modified 5-(halogen)uracil hybrids: DFT studies, Superlattices Microstruct. 65 (2014) 375-379.

[9] H.W. Kroto, J.R. Heath, S.C. Obrien, R.F. Curl, R.E. Smalley, C60: buckminsterfullerene, Nature 318 (1985) 162-163.

[10] S. Iijima, Helical microtubules of graphitic carbon, Nature 354 (1991) 56-58.

[11] L.B. Kiss, J. Söderlund, G.A. Niklasson, C.G. Granqvist, New approach to the origin of lognormal size distributions of nanoparticles, Nanotechnology 10 (1999) 25.

[12] M. Mirzaei, Investigating pristine and carbon-decorated silicon nanocones: DFT studies, Superlattices Microstruct. 58 (2013) 130-134.

[13] T. Mirkovic, M.L. Foo, A.C. Arsenault, S. Fournier-Bidoz, N.S. Zacharia, G.A. Ozin, Hinged nanorods made using a chemical approach to flexible nanostructures, Nat. Nanotechnol. 2 (2007) 565-569.

[14] W. Chen, H. Li, How does carbon nanoring deform to spiral induced by carbon nanotube?, Sci. Rep. 4 (2014) 3865.

[15] A.K. Geim, K.S. Novoselov, The rise of graphene, Nat. Mater. 6 (2007) 183-191.

[16] A. Pakdel, C. Zhi, Y. Bando, D. Golberg, Low-dimensional boron nitride nanomaterials, Mater. Today 15 (2012) 256-265.

[17] M. Mirzaei, Formations of boron-doped and nitrogen-doped silicon nanotubes: DFT studies, Superlattices Microstruct. 64 (2013) 52-57.

[18] Q. Wang, Y. Li, S. Jin, S. Sang, Catalyst-free hybridization of silicon carbide whiskers and expanded graphite by vapor deposition method, Ceram. Int. B 41 (2015) 14359-14366.

[19] J. Ding, C. Deng, W. Yuan, H. Zhu, X. Zhang, Novel synthesis and characterization of silicon carbide nanowires on graphite flakes, Ceram. Int. 40 (2014) 4001-4007.

[20] M. Mirzaei, Silicon carbide nanocones: computational analysis of chemical shieldings for pristine and boron/nitrogen decorated models, Superlattices Microstruct. 52 (2012) 523-527.

[21] M.T. Baei, M.R. Taghartapeh, E.T. Lemeski, A. Soltani, A computational study of adenine, uracil, and cytosine adsorption upon AlN and BN nano-cages, Physica B 444 (2014) 6-13.

[22] M.C. Amirani, T. Tang, J. Cuervo, Quantum mechanical treatment of binding energy between DNA nucleobases and carbon nanotube: a DFT analysis, Physica E 54 (2013) 65-71.

[23] M. Mirzaei, Formation of a peptide assisted bi-graphene and its properties: DFT studies, Superlattices Microstruct. 54 (2013) 47-53.

[24] R.V. Mundra, X. Wu, J. Sauer, J.S. Dordick, R.S. Kane, Nanotubes in biological applications, Curr. Opin. Biotechnol. 28 (2014) 25-32.

[25] O.O. Brovarets, R.O. Zhurakivsky, D.M. Hovorun, Structural, energetic and tautomeric properties of the $\mathrm{T} \cdot \mathrm{T} * / \mathrm{T} * \mathrm{~T}$ DNA mismatch involving mutagenic tautomer of thymine: a QM and QTAIM insight, Chem. Phys. Lett. 592 (2014) 247-255.

[26] M.J. Frisch, G.W. Trucks, H.B. Schlegel, G.E. Scuseria, M.A. Robb, J.R. Cheeseman, V.G. Zakrzewski, J.A. Montgomery, R.E. Stratmann, J.C. Burant, S. Dapprich, J.M. Millam, A.D. Daniels, K.N. Kudin, M.C. Strain, O. Farkas, J. Tomasi, V. Barone, M. Cossi, R. Cammi, B. Mennucci, C. Pomelli, C. Adamo, S. Clifford, J. Ochterski, G.A. Petersson, P.Y. Ayala, Q. Cui, K. Morokuma, D.K. Malick, A.D. Rabuck, K. Raghavachari, J.B. Foresman, J. Cioslowski, J.V. Ortiz, A.G. Baboul, B.B. Stefanov, G. Liu, A. Liashenko, P. Piskorz, I. Komaromi, R. Gomperts, R.L. Martin, D.J. Fox, T. Keith, M.A. Al-Laham, C.Y. Peng, A. Nanayakkara, C. Gonzalez, M. Challacombe, P.M.W. Gill, B. Johnson, W. Chen, M.W. Wong, J.L. Andres, C. Gonzalez, 
M. Head-Gordon, E.S. Replogle, J.A. Pople, Gaussian 98, Revision A.7, Gaussian, Inc., Pittsburgh, 1998.

[27] A. Yaraghi, O.M. Ozkendir, M. Mirzaei, DFT studies of 5-fluorouracil tautomers on a silicon graphene nanosheet, Superlattices Microstruct. 85 (2015) 784-788.

[28] S.F. Boys, F. Bernardi, Calculation of small molecular interactions by differences of separate total energies - some procedures with reduced errors, Mol. Phys. 19 (1970) 553-566.

[29] R.S. Drago, Physical Methods for Chemists, 2nd ed., Saunders College Publishing, 1992.
[30] E. Zurek, J. Autschbach, Density functional calculations of the 13C NMR chemical shifts in $(9,0)$ single-walled carbon nanotubes, J. Am. Chem. Soc. 126 (2004) 13079-13088.

[31] M. Mirzaei, M. Yousefi, M. Meskinfam, Chemical shielding properties for BN BP, AIN, and AlP nanocones: DFT studies, Superlattices Microstruct. 51 (2012) 809-813.

[32] M.K. Hazrati, N.L. Hadipour, Adsorption behavior of 5-fluorouracil on pristine B-, Si-, and Al-doped C60 fullerenes: a first-principles study, Phys. Lett. A 380 (2016) 937-941. 